\title{
Cross sectional stature and weight reference curves for the UK, 1990
}

\author{
J V Freeman, T J Cole, S Chinn, P R M Jones, E M White, M A Preece
}

\begin{abstract}
The current reference curves of stature and weight for the UK were first published in 1966 and have been used ever since despite increasing concern that they may not adequately describe the growth of present day British children. Using current data from seven sources new reference curves have been estimated from birth to 20 years for children in 1990. The great majority of the data are nationally representative. The analysis used Cole's LMS method and has produced efficient estimates of the conventional centiles and gives a good fit to the data. These curves differ from the currently used curves at key ages for both stature and weight. In view of the concerns expressed about the current curves and the differences between them and the new curves, it is proposed that the curves presented here should be adopted as the new UK reference curves.

(Arch Dis Child 1995; 73: 17-24)
\end{abstract}

Keywords: stature, weight, British children, reference data.

The reference curves of stature and weight currently used in the UK were first published in $1966 . .^{2}$ In 1976 they were redesigned for easier interpretation, ${ }^{3}$ but based on the same data. The Tanner-Whitehouse standards, as they are known, have been in use in the UK ever since. In recent years there has been increasing concern that they do not describe adequately the growth in stature and weight of present day British children. ${ }^{4-7}$ There are two potential reasons for this: the first is the secular trend towards earlier maturity and greater adult size $^{8-11}$ and the second that the data used to produce the charts came from children living in the south east of England, primarily London, so the sample was not nationally representative.

In view of these concerns a project was begun in 1991 to produce new reference curves of stature and weight for the UK, using up-to-date data that were as nationally representative as possible.

\section{Subjects and methods}

After a review of existing datasets the data for the construction of the reference curves were taken from seven sources: the Human Measurements Anthropometry and Growth (HUMAG) Research Group's children's growth studies and adult body dimensions studies, the Tayside Growth Study, the
National Study of Health and Growth (NSHG), the Department of Health survey of the statures and weights of British adults, the Cambridge Infant Growth Study and the Whittington birth data study. All measurements were made between 1978 and 1990 and, in total, comprise data from over 25000.

Most of the surveys contained a small proportion of non-white children, who were excluded due to known differences in growth and final shape and size between ethnic groups. ${ }^{12-14}$ The number of non-white children was too small to produce separate curves for each ethnic group, for example the NSHG had the highest percentage of non-white children, at $6 \%$.

\section{(1) HUMAG CHILDREN'S GROWTH STUDIES}

Three separate surveys were conducted by the HUMAG Research Group at Loughborough University, ${ }^{15}$ sponsored by a syndicate of British retailers and garment manufacturers. Together they covered the age range birth to 15.99 for girls and birth to 16.99 years for boys and their aim was to collect up-to-date information on all standard body measurements used for body composition, growth studies, and in the construction of garments for British children. The samples were selected to be nationally representative (including Wales and Scotland), with the sampling being multistage. For the boys 5 years and older data were collected in 1978; the country was divided into areas of similar population size (excluding Wales), within each a moderate to large area was selected and schools then selected from each chosen area. The procedure for the girls 5 years and older was the same, when they were measured in 1986, except that Wales was included in the sample. In 1987 two further samples were drawn, infants from birth to 1.99 years and toddlers from 2 to 4.99 years, both sexes (excluding Scotland). For these two surveys, 16 areas of approximately equal size were selected. Children were selected for measurement within these groups through various organisations: social service departments, nursery schools, National Childbirth Trust, and mother and toddler groups.

Altogether 9791 children were measured, 9282 were white and have been included in the present study. From these data the HUMAG Research Group produced for the British Standards Institution (BSI) British standards of body measurements for boys and girls from birth to 16.99 years (BS 7231, parts I and II). ${ }^{15}$ Other data collected included age, sex, area of residence and ethnic group, but no socioeconomic data. 
(2) HUMAG ADULTS ANTHROPOMETRIC MEASUREMENTS STUDIES

These studies covered the age range 16 to 64.99 years for men and 16 to 69.99 for women, and collected information on all the standard body measurements used in the manufacture of garments for the adult population of the UK. ${ }^{16}$ Each sample was a quota sample and was designed to be nationally representative of the socioeconomic mix of the general UK adult population (including Wales and Scotland). Initially the country was divided into regions of similar size and areas selected from within these, for both samples. For the men's sample, addresses were selected within these areas and the men were approached and measured at home. The fieldwork was carried out in 1984 and the results were published in January 1985. A total of 6684 men were measured but only the 1197 aged less than 20 are included in the current study. The women's sample was obtained by approaching women in the streets in the chosen areas and measuring them in selected department stores. The fieldwork was conducted in early 1987 and made available to the sponsors in September 1987, and of the total 6386 measured, the 793 white subjects aged less than 20 are included here. These data included information on age, sex, area of residence and ethnic group, but there were no socioeconomic data.

(3) NATIONAL STUDY OF HEALTH AND GROWTH The NSHG was set up in 1972 amid concern about the potentially adverse effect of changes in welfare policy governing the provision of milk and school meals in primary schools. It had the specific aim of developing a surveillance system of health and growth of primary schoolchildren and concentrated on stature as the major measure of nutritional status. Initially the samples were taken every year from England and Scotland (not Wales) until 1982. Since then, sampling in Scotland has continued to be annual whereas in England in even years the sampling is representative, but in odd years it is biased towards the inner cities and ethnic minorities, containing a disproportionate number of children from these groups. Employment exchange areas were taken as the sampling frame and an index of the socioeconomic status of the areas was calculated. The index values were then divided into six strata and areas sampled randomly from each. Within these areas, schools were then selected and all children in each selected school were measured. A total of 22 areas in England and 14 in Scotland were surveyed in this way. The two most recent representative samples from the NSHG were used covering the age range 4.5 to 11.99 , England 1990 and Scotland 1989-90, with a total of 10992 children measured of whom 10546 were white. An extensive questionnaire concerning the socioeconomic circumstances of each child was administered, and information on ethnic status, region of residence, age, and sex obtained.
(4) STATURES AND WEIGHTS OF ADULTS IN GREAT BRITAIN

The 1984 Department of Health survey was a representative survey of statures and weights of the British population aged $16-64 \cdot 99 .{ }^{17}$ It was initiated because of concern about increasing levels of obesity in the general adult population of Great Britain. The sampling was multistage covering all eligible individuals in a sample of 5000 households. The achieved sample was 10018 adults weighed and measured $(48 \%$ male) and of these the 464 men and 471 women who were white and aged below 20 years have been included. All interviews and measurements were taken in the respondent's own home. The fieldwork for the survey was undertaken in late 1980. Details of other data collected can be found in the Office of Population Censuses and Surveys report to the Department of Health and included extensive socioeconomic data and data on diet and lifestyle.

\section{(5) TAYSIDE GROWTH STUDY}

The Tayside Growth Study was established in 1989 to improve the efficiency of growth surveillance within the Tayside health region. It followed concern that the present growth curves were not representative of the population and their use was leading to an underreporting of the number of growth retarded children. Statures and weights were measured prospectively in the community, all children in Tayside aged $3,5,7,9,11$, and 14 being eligible for inclusion and data were collected between August 1989 and July 1990. The expected sample size was 26000 and of these 23046 children participated. Ascertainment was incomplete below 4.5 years, so data under this age have been excluded here. Due to the large number of participants only a $10 \%$ random sample of the remaining data have been included in the present analysis $(n=1624)$. Apart from date of birth, date of measurement, sex, and place of measurement no other data were available.

The number of infants in the HUMAG babies study during the first year was very small and no information on gestational age was recorded. As a result it was decided to augment it by using data from two studies of infants sampled at birth, both with large numbers and gestational age at birth recorded. One of these, the Cambridge Infants Growth Study contained serial data, with the children being followed up from four weeks after birth to between 2 and 7 years.

\section{(6) CAMBRIDGE INFANT GROWTH STUDY}

This study was begun in 1984 at the Medical Research Council's Dunn Nutrition Centre, Cambridge to study the effect of differences in infant feeding practices upon the pattern of normal infant growth adjusted for gestational age. The data are longitudinal with four cohorts recruited between January 1984 and September 1988 and a total of 252 infants 
Table 1 Numbers at each age contributing to the LMS analyses, by sex

\begin{tabular}{lrr}
\hline Age (years) & Boys & Girls \\
\hline 35 weeks-term & 161 & 139 \\
$0+$ & 721 & 680 \\
$0 \cdot 25+$ & 466 & 405 \\
$0 \cdot 50+$ & 467 & 423 \\
$0 \cdot 75+$ & 457 & 404 \\
$1+$ & 513 & 472 \\
$2+$ & 202 & 205 \\
$3+$ & 178 & 164 \\
$4+$ & 349 & 341 \\
$5+$ & 1145 & 1264 \\
$6+$ & 1163 & 1135 \\
$7+$ & 1243 & 1204 \\
$8+$ & 1213 & 1186 \\
$9+$ & 1264 & 1204 \\
$10+$ & 1227 & 1114 \\
$11+$ & 927 & 833 \\
$12+$ & 354 & 387 \\
$13+$ & 337 & 414 \\
$14+$ & 430 & 542 \\
$15+$ & 291 & 411 \\
$16+$ & 505 & 396 \\
$17+$ & 412 & 312 \\
$18+$ & 419 & 272 \\
$19+$ & 409 & 284 \\
\hline
\end{tabular}

followed up until between 2 and 7 years, though only the data to age 2 have been used here. In addition to extensive anthropometric data, gestational age and much socioeconomic data were recorded.

\section{(7) WHITTINGTON BIRTH DATA STUDY}

Birth anthropometry data were obtained from a fetal growth study carried out at the Whittington Hospital, London. ${ }^{18}$ The study took place over a six month period during 1987/8, and involved 999 infants of 32 weeks or greater gestational age. Of these, the 756 white babies were selected for the present study, the dataset including nine pairs of twins and one set of triplets. Measurements of weight at birth and length on day 2 were obtained by a single observer, and gestation (by last menstrual period confirmed by ultrasound) was recorded, along with the mother's age and parity.

The distribution of data by age for all the datasets combined is shown in table 1 .

\section{MEASUREMENT TECHNIQUE}

In all seven studies measurements of height and weight were made by specifically trained personnel using appropriate equipment. Length was measured supine until age 2 in all samples, and stature was measured standing in bare feet at all ages thereafter. In all samples except NSHG, Tayside, and Whittington length/ stature was measured to the nearest $\mathrm{mm}$. For NSHG and Tayside it was measured to the last completed $\mathrm{mm}$ and for the Whittington sample it was measured to the nearest $5 \mathrm{~mm}$. The children were stretched to reduce the amount of shrinkage due to posture and diurnal variation, although in the Department of Health Survey the adults were measured unsupported. The Tanner-Whitehouse stature charts give supine length until 2 years of age and stature thereafter with a discontinuity at 2 years. However, provided stature is measured correctly and the child stretched there should be negligible difference between length and stature in series of data treated cross sectionally. Indeed, during the recent construction of standards for growth of Swedish children, Lindgren et al attempted to estimate the size of the length/stature discontinuity and found no evidence of a difference and made no allowance for it in the subsequent charts. ${ }^{19} \mathrm{~A}$ less formal analysis of our own data also failed to demonstrate a discontinuity.

Weight was measured in nappies for the HUMAG infants, and in minimal underclothes for all other HUMAG children and adults, and NSHG children to the nearest 100 g. No adjustments were made for clothing. Tayside children were measured to the nearest $50 \mathrm{~g}$, with no adjustment for clothing. The adults in the Department of Health survey were measured clothed to the nearest $500 \mathrm{~g}$ and estimated clothing weight subsequently deducted. Whittington infants were measured naked to the nearest $10 \mathrm{~g}$. Infants in the Cambridge study were measured in light underclothes to the nearest $10 \mathrm{~g}$ and the clothing weight, also measured to the nearest $10 \mathrm{~g}$, was deducted.

As is usual in large cross sectional studies several measurement teams were necessary in most of the studies, notable exceptions being the Whittington and Cambridge studies where a single measurer was used in each case. However the teams were trained and tested for within and between observer error which were $\leqslant 0.4 \mathrm{~cm}$ for stature and $\leqslant 0.05 \mathrm{~kg}$ for weight in all cases.

\section{METHODS}

The data were examined for differences between datasets using multiple regression of log stature and log weight, adjusted for age group and geographical region. The log transform was used to adjust for heteroscedasticity and had the added benefit of expressing the dataset differences in relative (percentage) rather than absolute terms. Age was grouped by half year intervals, and region was coded into 11 standard regions: Greater London, South East excluding Greater London, South West, West Midlands, East Midlands, East Anglia, Wales, North West, Yorkshire and Humberside, Northern, and Scotland. Interactions between region and age, and between dataset and age, were non-significant.

The linear modelling procedure used for this part of the investigation produces estimates of the differences between the datasets, assumed to be constant (in percentage terms as explained above). Comparability between the datasets can thus be obtained by adding or subtracting the differences relative to a reference or baseline dataset. NSHG was chosen as the reference dataset as it was the most up-todate (1990). All observations in the other datasets were adjusted accordingly and the whole of the data were then pooled for subsequent analysis. This ensured that the impact of any gross methodological or secular differences between datasets would be minimised. The Whittington dataset was excluded from the dataset adjustment stage as it did not overlap with the other studies by age and no reliable estimate of its position relative to NSHG could be produced. However the weights of the Whittington infants were compared with the weights of a contemporaneous sample of infants from Newcastle upon Tyne. ${ }^{2021}$ For boys no significant difference between the two datasets was found, but for the girls the difference of $1 \cdot 7 \%$ was just significant at the $5 \%$ level, although unimportant clinically (55 g).

The production of reference curves for use in the monitoring of growth is greatly aided if the data used in their construction follow a Gaussian distribution. ${ }^{22}$ For stature this has been widely accepted as true, and previous centiles have been constructed on this basis. ${ }^{12}$ For other anthropometric variables this is not usually this case, and empirical reference centiles have commonly been constructed from the raw data. ${ }^{23}$ This however has the disadvantage that the extreme centiles are much less efficiently estimated with the centile 
Table 2 Percentage (SE) differences in stature, for each dataset relative to NSHG, adjusted for age and geographical region

\begin{tabular}{llr}
\hline Dataset & \multicolumn{1}{l}{ Boys } & \multicolumn{1}{l}{ Girls } \\
\hline HUMAG & & \\
$0-1.99$ & $-0.0(0 \cdot 4)$ & $0 \cdot 8(0 \cdot 4)$ \\
$2-4.99$ & $-0.5(0 \cdot 3)$ & $-0.0(0 \cdot 3)$ \\
$5+$ & $-1 \cdot 1(0 \cdot 1)$ & $-0.3(0 \cdot 1)$ \\
Adults & $-0.0(0 \cdot 3)$ & $0 \cdot 2(0 \cdot 4)$ \\
Department of Health adults & $-0.5(0 \cdot 3)$ & $-1 \cdot 0(0 \cdot 3)$ \\
Tayside & $-0.7(0 \cdot 2)$ & $-0.1(0 \cdot 2)$ \\
Cambridge & $-0.9(0 \cdot 3)$ & $-0.7(0 \cdot 3)$ \\
\hline
\end{tabular}

standard errors increasing steeply towards the tails of the distribution. ${ }^{24}$ Furthermore the construction of SD scores which are of much practical value in the assessment of growth is much easier for variables distributed in a Gaussian manner.

In order to resolve distributional concerns centiles curves were estimated using Cole's LMS method, 2526 which involves normalising the data at each age using a Box-Cox power transformation. The centiles at each age can then be summarised in terms of the Box-Cox power needed to make the distribution normal (called L), together with the median (M) and coefficient of variation (S) of the distribution. The fitting process ensures that the values of $\mathrm{L}$ $M$, and $S$ change smoothly with age so that they can be represented as smooth curves plotted against age. The three quantities provide the required centiles, using the formula:

$$
C_{100 \alpha}(t)=M(t)\left[1+L(t) S(t) z_{\alpha}\right]^{1 / L(t)}
$$

where $\mathrm{C}_{100 \alpha}(\mathrm{t})$ is the centile curve plotted against age $t, z_{\alpha}$ is the normal equivalent deviate for the centile (for example when $\alpha=0.97$ corresponding to the 97 th centile, $z_{\alpha}=1 \cdot 88$ ), and $L(t), M(t)$, and $S(t)$ are the fitted smooth curves plotted against age. Since these curves are smooth, the resulting centile curve is smooth as well.

There are three main advantages of this approach. Firstly it estimates extreme centiles more efficiently than the simpler 'sort and count' procedure, while allowing for skewness in the distribution; secondly it can generate any required centiles, not just the conventional set of seven; and thirdly, centiles constructed by the LMS method allow data to be converted directly to SD scores, using the formula:

$$
\mathrm{SD} \text { score }=\frac{[\text { Measurement } / M(t)]^{L(t)}-1}{S(t) L(t)}
$$

where measurement is the child's measurement (stature or weight), and $\mathrm{L}(\mathrm{t}), \mathrm{M}(\mathrm{t})$, and

\begin{tabular}{|c|c|c|c|c|c|c|c|c|c|}
\hline \multirow{2}{*}{$\begin{array}{l}\text { Age } \\
\text { (years) }\end{array}$} & \multicolumn{3}{|l|}{1965} & \multicolumn{3}{|l|}{1990} & \multicolumn{3}{|c|}{ Differences } \\
\hline & $3 r d$ & 50 th & 97 th & $3 r d$ & $50 t h$ & 97th & $3 r d$ & $50 t h$ & 97th \\
\hline \multicolumn{10}{|l|}{ Boys } \\
\hline & $79 \cdot 7$ & 85.9 & $92 \cdot 1$ & $81 \cdot 1$ & $87 \cdot 1$ & 93.0 & 1.4 & $1 \cdot 2$ & 0.9 \\
\hline 5 & $99 \cdot 4$ & $108 \cdot 3$ & $117 \cdot 2$ & $101 \cdot 1$ & $109 \cdot 7$ & $118 \cdot 2$ & 1.7 & 1.4 & $1 \cdot 0$ \\
\hline 11 & $129 \cdot 4$ & 141.9 & 154.4 & 130.8 & $143 \cdot 2$ & 155.8 & $1 \cdot 4$ & $1 \cdot 3$ & 1.4 \\
\hline 16 & 158.9 & $172 \cdot 2$ & 185.5 & 158.9 & 173.0 & $187 \cdot 4$ & 0.0 & 0.8 & 1.9 \\
\hline 18 & $162 \cdot 2$ & $174 \cdot 7$ & $187 \cdot 2$ & 163.3 & 176.4 & 189.7 & $1 \cdot 1$ & $1 \cdot 7$ & $2 \cdot 5$ \\
\hline \multicolumn{10}{|l|}{ Girls } \\
\hline 2 & $78 \cdot 4$ & $84 \cdot 6$ & $90 \cdot 8$ & $79 \cdot 9$ & $85 \cdot 7$ & 91.5 & 1.5 & $1 \cdot 1$ & 0.7 \\
\hline 5 & $98 \cdot 2$ & $107 \cdot 2$ & $116 \cdot 1$ & $100 \cdot 2$ & $108 \cdot 7$ & $117 \cdot 1$ & $2 \cdot 0$ & 1.5 & 1.0 \\
\hline 11 & $129 \cdot 4$ & $142 \cdot \overline{7}$ & 155.8 & 130.9 & 143.8 & 156.9 & 1.5 & $1 \cdot 1$ & $1 \cdot 1$ \\
\hline 16 & 150.9 & $162 \cdot 2$ & 173.5 & 151.6 & 163.0 & 174.6 & 0.7 & 0.8 & $1 \cdot 1$ \\
\hline 18 & - & - & - & $152 \cdot 3$ & 163.6 & 175.0 & - & - & - \\
\hline
\end{tabular}

Table 3 Stature (cm), 1990 centiles compared with 1965 centiles at key ages

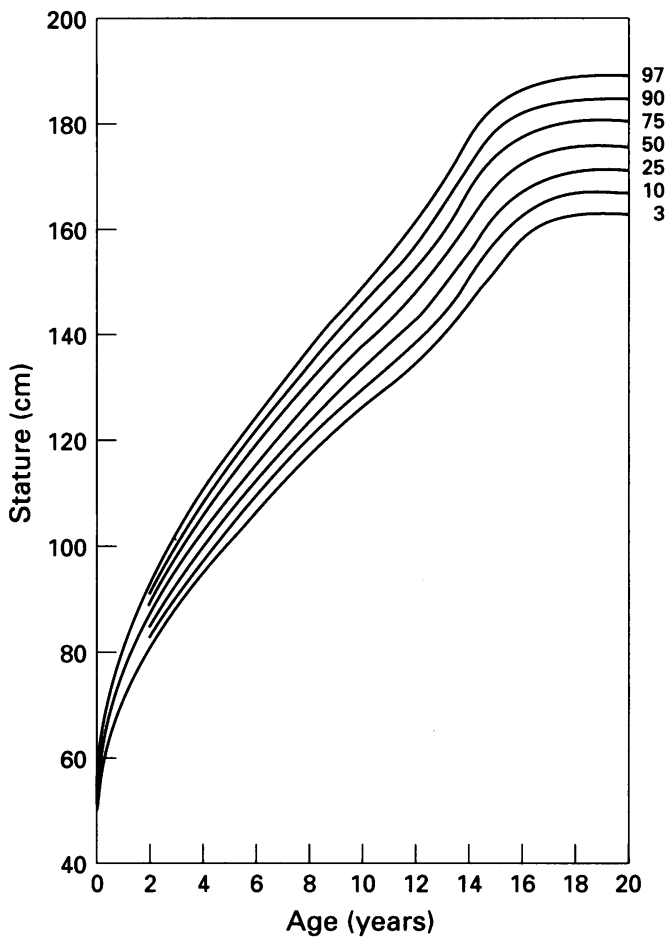

Figure 1 Height centiles for British boys, 1990. The 3rd, 10th, 25th, 50th, 75th, 90th, and 97th centiles are shown except before the age of 2 years where only the 3rd, 50th, and 97 th centiles are depicted, for clarity.

$\mathrm{S}(\mathrm{t})$ are values read from the smooth curves for the child's age and sex.

To test the goodness of fit of the model, the data were converted to SD scores using formula (2), grouped into yearly intervals, and the proportion falling below the 3rd, 50th, and 97th centiles (that is $\mathrm{SD}$ scores below $-1 \cdot 88,0$, and 1.88 respectively) calculated. The observed numbers falling below the centiles were then compared with the expected number to produce a $\chi^{2}$ statistic with 1 degree of freedom for each age and centile group. The distribution of these individual $\chi^{2}$ statistics was then examined.

All analyses were carried out for the sexes separately.

\section{Results}

STATURE

The percentage differences between datasets for stature are shown in table 2 expressed relative to NSHG. These differences were used to adjust the observations in each dataset to those of NSHG. This produced a single adjusted dataset containing all observations for the subsequent LMS and goodness of fit analysis. Examining the differences in table 2, all the boys and most of the girls in other datasets were shorter than the NSHG children. Only the BSI babies aged 1-1.99 and HUMAG adults were taller.

The Box-Cox power transformations $L$ for stature were not significantly different from 1 (indicating zero skewness) and were set to 1 at all ages. Figure 1 shows the resultant stature centiles for UK boys 1990, using the conventional centiles (3rd, 10th, 25th, 50th, 75th, 90th, and 97th).

For boys' stature, the 1990 50th centiles is greater than that of the Tanner-Whitehouse 


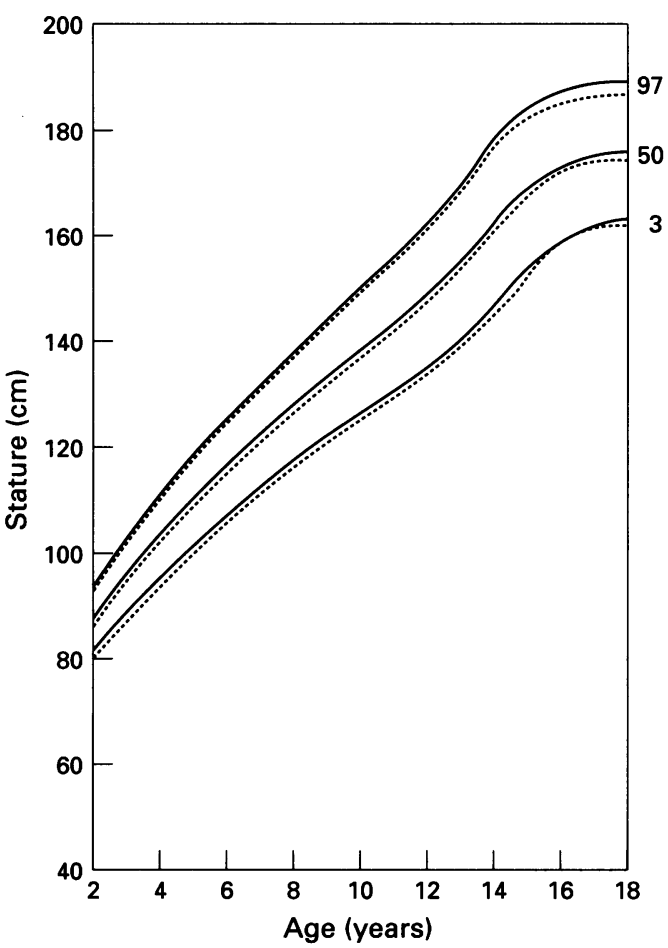

Figure 2 Comparison of the 1990 height centiles (boys) with the comparable Tanner-Whitehouse cross sectional data. Only ages 2-18 are shown as Tanner-Whitehouse data for stature is only available in this range. The solid line represents the 1990 data and the broken line Tanner-Whitehouse.

standards at all ages, the smallest difference being $0.8 \mathrm{~cm}$ at age 16 and the greatest $1.7 \mathrm{~cm}$ at age 18 (table 3 and fig 2). The 3rd and 97th centiles were also greater by similar amounts apart from the 3 rd centile at age 16 which showed no difference. A similar pattern emerges for girls with the 3rd, 50th, and 97th centiles of the new charts greater than TannerWhitehouse at all ages. The largest difference in the 50th centile of $1.5 \mathrm{~cm}$ occurred at age 5 and the smallest, of $0.8 \mathrm{~cm}$, at age 16 .

\section{WEIGHT}

As with stature, for weight the majority of both girls and boys were lighter than the NSHG children (table 4). Only the BSI toddlers aged 2-4.99, both sexes, and Tayside girls were heavier.

The smoothed $\mathrm{L}$ values for weight varied between -1.16 and 0.53 and were highly significantly different from 1 . Figure 3 shows the resultant weight centiles for boys.

The differences between the TannerWhitehouse standards and the new centiles of weight were not so marked for boys (table 5

Table 4 Percentage (SE) differences in weight, for each dataset relative to $\mathrm{NSHG}$, adjusted for age and geographical region

\begin{tabular}{|c|c|c|}
\hline Dataset & Boys & Girls \\
\hline \multicolumn{3}{|l|}{ HUMAG } \\
\hline $0-1.99$ & $-3 \cdot 0(1 \cdot 4)$ & $-3 \cdot 1(1 \cdot 5)$ \\
\hline $2-4.99$ & $0 \cdot 3(1 \cdot 2)$ & $0.5(1.3)$ \\
\hline $5+$ & $-1.9(0.4)$ & $-3.0(0.4)$ \\
\hline Adults & $-0.4(1.0)$ & $-1 \cdot 1(1 \cdot 4)$ \\
\hline Department of Health adults & $-1 \cdot 2(1 \cdot 1)$ & $-1 \cdot 1(1 \cdot 3)$ \\
\hline Tayside & $-0.5(0.6)$ & $1.5(0.7)$ \\
\hline Cambridge & $-0.7(1 \cdot 1)$ & $-3 \cdot 5(1 \cdot 2)$ \\
\hline
\end{tabular}

and fig 4). The 1990 3rd centile is greater than Tanner-Whitehouse at all ages apart from at age 16 , though the difference is only $0.8 \mathrm{~kg}$. The 50th centile for 1993 is greater than Tanner-Whitehouse at all ages apart from age 2. The 97th centile is similar to the 50th, a negative difference at age 2 increasing to a positive difference at age 18 . For girls the differences are relatively small. The 1990 3rd centile of weight was less than TannerWhitehouse at all ages except ages 2 and 11 . The 50th centile was greater at ages 11 and 18 . For the 97th centile the pattern was different again with the 1990 centile being greater than Tanner-Whitehouse at ages 2, 5, and 18.

AGE AT PEAK HEIGHT VELOCITY

Though in cross sectional data the magnitude of the adolescent growth spurt is greatly diminished, its timing remains the same. To examine the possibility of earlier maturity, annual stature velocities were calculated from the medians at each age. These showed that peak growth at adolescence occurred earlier than for the Tanner-Whitehouse standards, at 13.5 years for boys (compared with 13.95 years for boys in Tanner-Whitehouse). For girls however there was no single discernible peak, with a plateau between 10 and 12 years (compared with a peak at $\mathbf{1 1 . 9 5}$ years for girls in Tanner-Whitehouse).

\section{GOODNESS FOR FIT}

For boys stature the $\chi^{2}$ values varied between 0 and 5.64 with a median of 0.33 , and the spread of values was compatible with a standard $\chi^{2}$ distribution on 1 degree of freedom. The same was true for girls stature and also for weight, both sexes. The values varied between 0 and

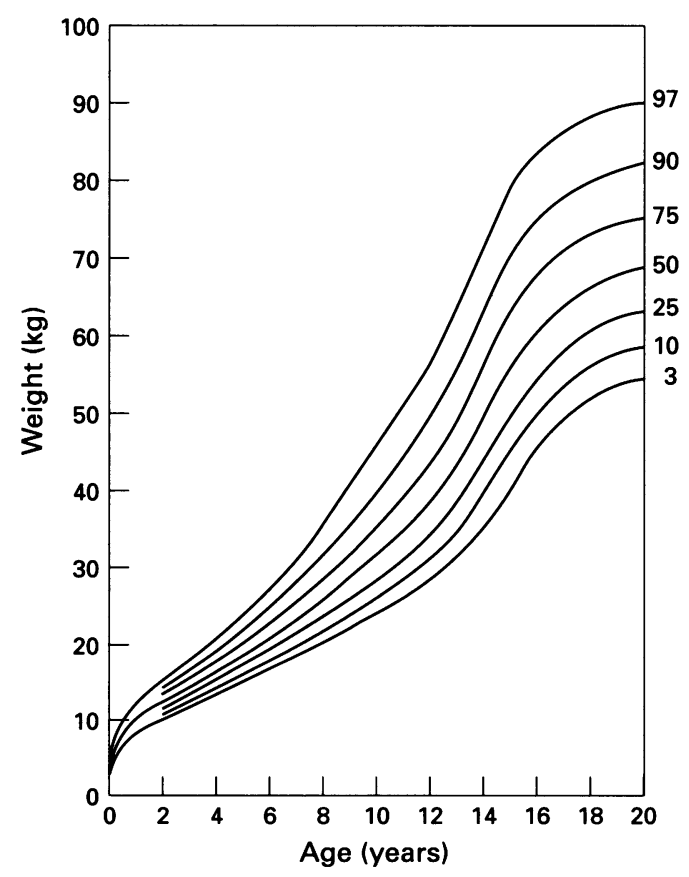

Figure 3 Weight centiles for British boys, 1990. The 3rd, 10th, 25th, 50th, 75th, 90th, and 97th centiles are shown except before the age of 2 years where only the $3 r d, 50 t h$, and 97 th centiles are depicted, for clarity. 
Table 5 Weight (kg), 1990 centiles compared with 1965 centiles at key ages

\begin{tabular}{|c|c|c|c|c|c|c|c|c|c|}
\hline \multirow{2}{*}{$\begin{array}{l}\text { Age } \\
\text { (years) }\end{array}$} & \multicolumn{3}{|l|}{1965} & \multicolumn{3}{|l|}{1990} & \multicolumn{3}{|c|}{ Differences } \\
\hline & $3 r d$ & 50 th & 97th & $3 r d$ & $50 t h$ & 97th & $3 r d$ & 50 th & 97th \\
\hline \multicolumn{10}{|l|}{ Boys } \\
\hline 2 & $10 \cdot 2$ & $12 \cdot 7$ & $15 \cdot 6$ & $10 \cdot 2$ & $12 \cdot 4$ & $15 \cdot 2$ & 0.0 & -0.3 & -0.4 \\
\hline 5 & $14 \cdot 4$ & 18.5 & 23.2 & $15 \cdot 1$ & $18 \cdot 6$ & $23 \cdot 6$ & 0.7 & 0.1 & 0.4 \\
\hline 11 & 24.9 & 33.6 & $49 \cdot 5$ & $26 \cdot 1$ & $34 \cdot 5$ & 50.9 & $2 \cdot 0$ & 0.9 & 1.4 \\
\hline 16 & $45 \cdot 7$ & $59 \cdot 6$ & $78 \cdot 6$ & 44.9 & $60 \cdot 2$ & $83 \cdot 2$ & -0.8 & 0.6 & $4 \cdot 8$ \\
\hline 18 & 50.0 & 63.0 & $81 \cdot 0$ & $52 \cdot 0$ & $66 \cdot 2$ & 87.9 & $2 \cdot 0$ & $3 \cdot 2$ & 6.9 \\
\hline \multicolumn{10}{|l|}{ Girls } \\
\hline 2 & 9.7 & $12 \cdot 2$ & 14.9 & $10 \cdot 0$ & $12 \cdot 1$ & 14.9 & $0 \cdot 1$ & $-0 \cdot 1$ & 0.0 \\
\hline 5 & $14 \cdot 6$ & $18 \cdot 3$ & $23 \cdot 3$ & 14.5 & $18 \cdot 2$ & 23.9 & $-0 \cdot 1$ & -0.1 & 0.6 \\
\hline 11 & $24 \cdot 7$ & $35 \cdot 2$ & $55 \cdot 7$ & $26 \cdot 0$ & 35.9 & $53 \cdot 6$ & 1.3 & $0 \cdot 7$ & $-2 \cdot 1$ \\
\hline 16 & $44 \cdot 6$ & $55 \cdot 8$ & 74.5 & $42 \cdot 8$ & 55.3 & $74 \cdot 1$ & -1.8 & -0.5 & -0.4 \\
\hline 18 & $46 \cdot 0$ & $56 \cdot 6$ & $75 \cdot 0$ & $44 \cdot 7$ & $57 \cdot 2$ & $76 \cdot 3$ & $-1 \cdot 3$ & 0.6 & $1 \cdot 3$ \\
\hline
\end{tabular}

6.98 with a median of 0.36 for girls' stature, 0 and 5.91 with a median of 0.36 for boys' weight, and 0 and 5.07 with a median of 0.45 for girls' weight. The spread of the values showed no distinct patterns with age for either sex or variable.

\section{Discussion}

Presented in this paper are contemporary cross sectional reference centiles for Great Britain. They were constructed using up-to-date national, randomly sampled data, although some more geographically restricted data were used to supplement certain ages and national groups. The Whittington dataset, though not nationally representative, was verified against a representative sample of children from Newcastle and was shown to be clinically not different. Only data from white subjects were used in preparing the charts. The number of non-whites was too small to produce separate reference data for each ethnic group, and to have included them in the analyses might have artificially increased the variance of the centiles due to the potential heterogeneity of growth with ethnicity. ${ }^{12-14}$ The charts are for 1990 , the year of the NSHG study, to which the other datasets were adjusted. Cole's LMS method was used for centile construction and was demonstrated to produce centiles which were representative of the data from which they were derived.

The 3rd, 50th, and 97th centiles have been shown to be greater than the TannerWhitehouse standards at most ages for stature, and to a lesser extent, for weight. However compared with the Tanner-Centiles there appears to be a change in the shape of the distribution of both stature and weight with age, with the differences between the two sets of centiles being large at certain ages and almost negligible at others. This corresponds with findings from The Netherlands where a changing relationship between stature and weight and age compared with previous generations was found during construction of their current growth centiles. ${ }^{27}$ It could be argued that the differing pattern of growth over time is an artifact of the method of construction employed or sample selection. However the Dutch standards were constructed using methodology similar to that of Tanner et al ${ }^{1} 2$ rather than LMS, with some fitting by eye for both stature and weight. In addition the goodness of fit analysis suggests that the LMS model faithfully represents the data.
The overall increase in stature between 1966 and 1990 reflects the trend towards earlier maturity (in boys at least) and greater adult stature and weight nowadays compared to previous generations. This secular trend leads to increased stature and weight at any given age, over time. Rona and Altman compared the results of NSHG 1972 and TannerWhitehouse and found no difference. ${ }^{28}$ They speculated that this lack of difference could be due to a 'catching up' of the English average to that of the wealthier Tanner-Whitehouse sample. Furthermore, since the data used to produce the Tanner-Whitehouse charts came from children living in the south east of England, primarily London, the original sample was not nationally representative. ${ }^{29}$

Infant feeding practices have altered since the time of the construction of the TannerWhitehouse charts, when most infants were almost exclusively bottle fed. Many more babies are now breast fed, in line with government health recommendations, and infant feeding formulas currently available more closely resemble breast milk. These differences in nutritional patterns have been shown to affect the pattern of growth during infancy causing some researchers to question the validity of the Tanner-Whitehouse charts in infancy. ${ }^{30}$ Using data on Cambridge infants, the majority of whom were breast fed, Whitehead et al demonstrated that their growth was initially greater than the TannerWhitehouse standards but then declined such that for weight at 3 months the Cambridge 50th centile was on the Tanner-Whitehouse 60 th, but by the age of 10 months it had fallen to nearer the Tanner-Whitehouse 25th. ${ }^{7}$ Length was similar. They concluded that it was inappropriate to use the TannerWhitehouse reference curves for infants in 1989.

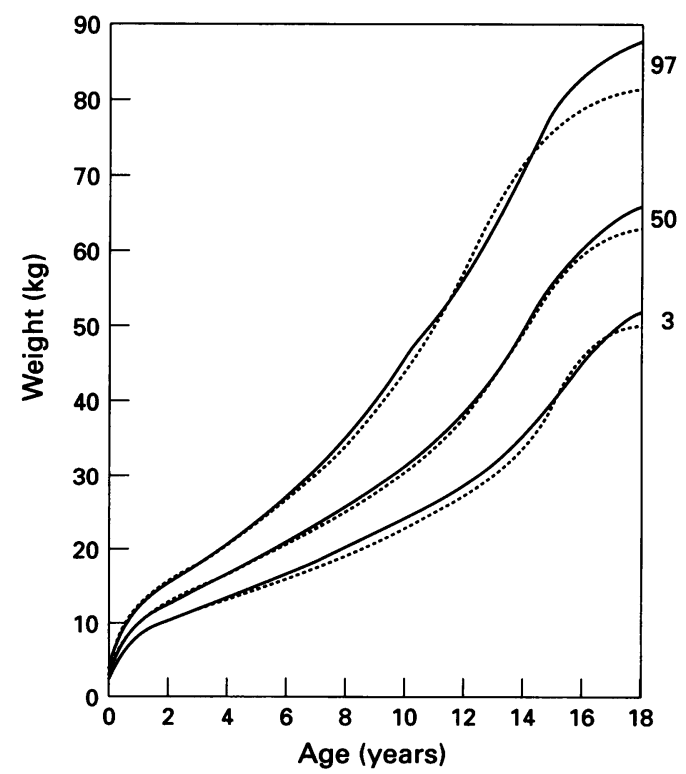

Figure 4 Comparison of the 1990 weight centiles (boys) with the comparable Tanner-Whitehouse cross sectional data. Only ages 0-18 are shown as Tanner-Whitehouse data for weight is only available in this range. The solid line represents the 1990 data and the broken line Tanner-Whitehouse. 
More recently Wright et al have compared the Tanner-Whitehouse, American NCHS, and Cambridge weight standards, using data from a cohort of infants resident in Newcastle upon Tyne in $1989 .{ }^{31}$ As with the Cambridge study, they showed that the growth in weight of the Newcastle infants matched the TannerWhitehouse standards poorly, with increased growth until 3 months and then a decrease to 18 months. This difference in the pattern of growth was reflected in the percentage falling outside the 3 rd and 97 th centiles. The authors concluded similarly to Whitehead et al that changes in infant feeding practices had altered the pattern of infant weight gain, and made the development of new growth standards necessary.

Using data on school entrants in the Southampton and Winchester health districts Voss et al showed that the percentage of the population falling below the 3rd centile of the Tanner-Whitehouse charts for stature was $1 \cdot 4 \% .^{5}$ This, they suggested, confirmed that their 5 year olds were taller than those of 20 years ago, and implied that the continued use of the Tanner-Whitehouse curves caused up to half the children who should be investigated for short stature to be excluded. Buckler conducted a similar analysis of school entrants in Leeds and found that they were similar in the Tanner-Whitehouse children of 25 years previously. ${ }^{6}$ Given the secular trend in stature and weight over this period, he concluded that the lack of contrast between Leeds and the Tanner-Whitehouse children could be attributed to the growth of Leeds schoolchildren running 25 years behind their southern counterparts.

For children aged 4.5 to 12 years, data from NSHG have been used to demonstrate a secular trend in the growth of primary schoolchildren, from its inception in 1972 to the present day. ${ }^{4}$ The differences ranged from just over half a centimetre in the youngest girls to more than a centimetre in the oldest boys. There were also differences between regions of the country and between ethnic groups. The regional differences were compatible with those found by Buckler for the Leeds schoolchildren. The authors suggested revision of the Tanner-Whitehouse reference curves. They also suggested that the construction of separate charts for different regions of the country deserved consideration, together with charts for different ethnic groups, specifically white and Afro-Caribbean subjects. However there are practical problems with this suggestion. The definition of ethnic groups would be confounded by issues of intermarriage and whether the standards should reflect first or subsequent generations. In addition, the geographical effects are complex: what standards should be used for a Cumbrian born child who now lives in Surrey?

The LMS method assumes the data can be normalised by means of a Box-Cox transformation. The L curve represents the transformation needed at any given age to achieve this and thus provides an estimate of the changing skewness of the data during childhood. Cole and Green have emphasised the usefulness of the maximum likelihood estimate of $\mathrm{L}$ as both minimising the skewness and optimising the fit to normality. ${ }^{26}$ This latter point was not mentioned by Van't Hof et al when they originally proposed using the Box-Cox power transformation. ${ }^{22}$ They considered the $\mathrm{L}$ curve to be of only marginal importance with no biological meaning, unlike LMS for which its use is central to the methodology. This information on skewness is not provided by other methods of centile production. ${ }^{25}$ The $M$ curve is exactly equivalent to the median curve of the variable, while the $S$ curve representing the coefficient of variation provides an estimate of the variance of the data which is relatively independent of the mean.

The $\mathrm{L}$ curve, combined with the $\mathrm{M}$ and $\mathrm{S}$ curves, provides all the information necessary to produce both SD scores and exact centile positions for data from individual children. The advantage of being able to convert all data to SD scores should be emphasised as this is a realistic way of performing subsidiary adjustment for ethnic or geographic effects. In addition, the assessment of children with suspected abnormal growth or from special subpopulations can be greatly aided by expressing stature and weight in terms of SD scores. A change in SD score is much easier to quantify than a change in centile position.

Recently, Cole suggested an alternative set of nine centile curves for growth charts which seem particularly relevant to cross sectional charts for community use. ${ }^{32}$ They are constructed by maintaining a constant $0.67 \mathrm{SD}$ units between curves giving the 0.4 th, 2 nd, 9th, 25th, 50th, 75th, 91st, 98th, and 99.6th centiles. As discussed by Cole these show significant advantages over the conventional seven centiles. In particular they provide a satisfactory, graded area for discussions about referral. Children whose statures fall below the $0 \cdot 4$ th centile $(4 / 1000)$ require immediate referral, those between the 0.4 th and 2 nd centile close observation, and those above the 2 nd less serious concern. These centiles have been used for the published version of the charts, which are obtainable from Harlow Printing Ltd, Maxwell Street, South Shields, NE33 4PX. In this paper the, conventional seven centile lines have been used to allow comparison with the Tanner-Whitehouse data.

Much time has elapsed since the construction of the Tanner-Whitehouse charts. Given the secular trend in growth over this period, it is not appropriate to use the TannerWhitehouse charts for present day British children. In addition, the shortcomings of the data used in their construction have been discussed. Though some of the data used for the new charts have come from non-nationally representative groups, the means of each dataset (except Whittington) have been adjusted to reflect the nationally representative NSHG. This situation is not ideal, but in the absence of a national growth survey, it is the best available. The new cross sectional community based charts should provide an essential tool for child health workers in assessing 
the growth and physical development of British children in the $1990 \mathrm{~s}$.

The data, as centiles, means, and SD or LMS coefficients are available to bona fide research workers and health professionals on application to the Child Growth Foundation, 2 Mayfield Avenue, Chiswick, London W4 1 PW.

JVF was supported by a generous grant from the Child Growth Foundation. Permission to use the Whittington dataset was kindly given by $\mathrm{G}$ Henson. The Department of Health gave was kindly given by G Henson. The Department of Health gave permission to use NSHG data. Material from the Heights and Weights of Adults in Great Britain Survey was made available
through the Office of Population Censuses and Surveys and the through the Office of Population Censuses and Surveys and the
ESRC Data Archive and has been used with permission. Drs ESRC Data Archive and has been used with permission. Drs NG Norgan and RH Hooper played a major part in the
HUMAG studies and Professor MJR Healy contributed greatly in the early stages by scrutinising candidate datasets and aiding in the eventual selection of data for analysis.

1 Tanner JM, Whitehouse RH, Takaishi M. Standards from birth to maturity for height, weight, height velocity, and weight velocity: British children, 1965. Arch Dis Child weight velocity: B

2 Tanner JM, Whitehouse RH, Takaishi M. Standards from birth to maturity for height, weight, height velocity, and birth to maturity for height, weight, height velocity, and weight velocity: B

3 Tanner JM, Whitehouse RH. Clinical longitudinal standards for height, weight, height velocity, weight velocity, and stages of puberty. Arch Dis Child 1976; 51: 170-9.

4 Chinn S, Price CE, Rona RJ. Need for new reference curves for height. Arch Dis Child 1989; 64: 1545-53.

5 Voss LD, Wilkin TJ, Betts PR. Do we need new growth charts? Lancet 1987; ii: 447-8.

6 Buckler JMH. Are Tanner growth charts applicable to children at school entry in Leeds? Arch Dis Child 1985; 60: $1188-90$.

7 Whitehead RG, Paul AA, Ahmed EA. Present-day infant feeding practice' and its influence on infant growth. London: Department of Health and Social Security, 1987.

8 Voss LD, Walker J, Lunt H, Wilkin T, Betts P. The Wessex Growth Study: first report. Acta Paediatr Scand 1989; 349 (suppl): 65-72.

9 Tanner JM. Growth at adolescence. 2nd Ed. Oxford: Blackwell, 1962.

10 Chin S, Rona RJ. The secular trend in the height of primary school children in England and Scotland from 1972-1980. Ann Hum Biol 1984; 11: 1-16.

11 Chinn S, Rona RJ, Price CE. The secular trend in primary school children in England and Scotland 1972-79 and 1979-86. Ann Hum Biol 1989; 16: 387-95.

12 Rona RJ, Chinn S. National Study of Health and Growth: social and biological factors associated with height of children from ethnic groups living in England. Ann Hum Biol 1986; 13: 453-71.

13 Rona RJ, Chinn S. National Study of Health and Growth: social and biological factors associated with weight-forheight and triceps skinfold of children from ethnic groups in England. Ann Hum Biol 1987; 14: 231-48.

14 Eveleth $\mathrm{PB}$, Tanner JM. Worldwide variation in human growth. IPB Programme 8. London: Cambridge Press, 1976.
15 British Standards Institution. Body measurements of boys and girls from birth to up to 16.9 years. (Part 1: Information in the form of tables, ISBN 0580 17752. Part 2: Recommendations of body dimensions for children, ISBN

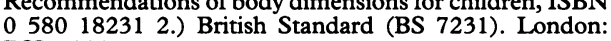
BSI, 1990 .

16 Jones PRM, Norgan NG, Hunt MJ, Hooper RH. British size surveys (computer files). Loughborough: Loughborough Consultants (distributor), 1993.

17 Knight I. The heights and weights of adults in Great Britain. London: HMSO, 1984. (Office of Population Censuses and Surveys.)

18 Colley NV, Tremble JM, Henson GL, Cole TJ. Head circumference/abdominal circumference ratio, ponderal index and fetal malnutrition. Should head circumference/abdominal circumference ratio be abandoned? $\mathrm{Br} \mathcal{F}$ Obstet Gynaecol 1991; 98: 524-7.

19 Lindgren G, Aurelius G, Tanner JM, Healy MJR. Standards for height, weight and head circumference for
one month to six years based on Stockholm children born in 1980. Acta Paediatr 1994; 83: 360-6.

20 Wright CM, Matthews JNS, Waterston A, Aynsley-Green A. What is a normal rate of weight gain in infancy? Acta Paediatr 1994; 83: 351-6.

21 Wright CM, Waterston A, Aynsley-Green A. Effect of deprivation on weight gain in infancy. Acta Paediatr 1994; 83: 357-9.

22 Van't Hof MA, Wit JM, Roede MJ. A method to construct age references for skewed skinfold data, using Box-Cox transformations to normality. Hum Biol 1985; 57: 131-9.

23 Tanner JM, Whitehouse RH. Standards for subcutaneous fat in British children. Percentiles for thickness of skinfolds over triceps and below scapula. $B M \mathcal{F} 1962$; $\mathrm{i}$ : 446-50.

24 Healy MJR. Notes on the statistics of growth standards. Ann Hum Biol 1974; 1: 41-6.

25 Cole TJ. Fitting smoothed centile curves to reference data. fournal of the Royal Statistical Society (A) 1988; 151: 385-418.

26 Cole TJ, Green PJ. Smoothing reference centile curves: the LMS method and penalized likelihood. Stat Med 1992; 11: 1305-19.

27 Roede MJ, Van Wieringen JC. Growth diagrams 1980; Netherlands third nation-wide survey. Tijdschrift voor Netherlands third nation-wide survey. Tijdsch
Sociale Gezondheidzorg 1985; 63 (suppl): 1-34.

28 Rociale Gezondheidzorg $1985 ; 63$ (suppl): 1-34. Growth: standards of attained height, weight and triceps skinfold in English children 5 to 11 years old. Ann Hum Biol 1977; 4: 501-23.

29 Chinn S. Longitudinal studies: design and analysis. Rev Epidemiol Sante Publique 1989; 37: 431-41.

30 Cole TJ, Paul AA, Eccles M, Whitehead RG. The use of a multiple growth standard to highlight the effects of diet and infection on growth. In: Tanner JM, ed. Auxology 88: perspectives in the science of growth and development. London: Smith-Gordon, 1989: 91-100.

31 Wright CM, Waterston A, Aynsley-Green A. Comparison of the use of Tanner and Whitehouse, NCHS, and Cambridge standards in infancy. Arch Dis Child 1993; 69: 420-2.

32 Cole TJ. Do growth chart centiles need a facelift? $B M F$ 1994; 308: 641-2. 